\title{
Paideusis
}

\section{Hanging Together with Richard Rorty}

\section{Dennis Cato}

Volume 11, Number 1, 1997

URI: https://id.erudit.org/iderudit/1073176ar

DOI: https://doi.org/10.7202/1073176ar

See table of contents

Publisher(s)

Canadian Philosophy of Education Society

ISSN

0838-4517 (print)

1916-0348 (digital)

Explore this journal

Cite this article

Cato, D. (1997). Hanging Together with Richard Rorty. Paideusis, 11(1), 19-32.

https://doi.org/10.7202/1073176ar

(c) Dennis Cato, 1997

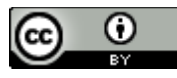

This document is protected by copyright law. Use of the services of Erudit (including reproduction) is subject to its terms and conditions, which can be viewed online.

https://apropos.erudit.org/en/users/policy-on-use/
This article is disseminated and preserved by Érudit.

Érudit is a non-profit inter-university consortium of the Université de Montréal, Université Laval, and the Université du Québec à Montréal. Its mission is to promote and disseminate research.

https://www.erudit.org/en/ 


\section{Hanging Together with Richard Rorty}

\section{Dennis Cato, Lachine, Quebec}

Traditionally, philosophy was thought to have as its objects of study the nature and purpose of human beings, the criteria of knowledge, questions of morality, and the like. In addition, it was thought that its standing as an autonomous discipline was established by its distinctive method of enquiry, one concerned with the clarification of meaning and the justification of claims to know. For Richard Rorty, however, it is just this traditional view of philosophy which should be rejected, starting with "the image of man as possessor of a Glassy Essence, suitable for mirroring nature with one hand while holding holding on to it with the other."1 For Rorty, once we release the view that human beings have an essence, all the other notions associated with the traditional view can also be dropped, principal among which is the claim of a distinctively philosophical knowledge about the nature of knowing. ${ }^{2}$

Once one has abandoned the notion that philosophers know something about knowing which nobody else knows and that there is a distinct philosophical method, technique, or point of view, then what follows is that one should also drop the view that philosophers have a special kind of knowledge about anything at all from which they can draw "relevant conclusions." However, several questions arise from such a conclusion. Independently of some sort of philosophical method or philosophical point of view, how does Rorty know that human beings do not possess an essence? How does he know that philosophers do not know something about knowing which nobody else knows? Does Rorty know something about knowing which nobody else knows, and if he does, how did he come to know it? If he does not, should his voice have an overriding claim on our attention?

Once the traditional conceptions and functions of philosophy are jettisoned, what remains, according to Rorty, is the "culture critic" who

feels free to comment on anything at all. He is a pre-figuration of the all-purpose intellectual of a post-Philosophical culture, the philosopher who has abandoned pretensions to Philosophy. ${ }^{3}$

But what does the all-purpose intellectual do when, having abandoned pretensions to Philosophy, he or she proceeds to comment on anything at all? Lacking a special kind of knowledge about knowledge and a grasp of a distinctive philosophical point of view, how does the culture critic draw relevant conclusions?

I argue that Rorty's cultural critic is not, as he suggests, the "all-purpose intellectual of a post-Philosophical culture" and, more specifically, that neither as "The Critic" nor in his subsequent embodiments as "The Metaphysician" and "The Ironist" has "abandoned pretensions to Philosophy." 4 On the contrary, in his articulation of their positions, I suggest that Rorty employs precisely those "pretensions" he claims the "post-Philosophical culture" has abandoned. These can be found in Rorty's concept of "hanging together" and my argument proceeds by analysing that concept. 
"Pragmatism," for Rorty,

denies the possibility of getting beyond the Sellarsian notion of 'seeing how things hang together'-which, for the bookish intellectual of recent times, means seeing how all the various vocabularies of all the various epochs and cultures hang together. 5

Getting beyond the possibility of seeing how things hang together was the "major pretension of Philosophy," and this is just what The Critic has abandoned. Consequently, his speciality

is seeing how things hang together. He is the person who tells you how all the ways of making things hang together hang together. But, since he does not tell you about how all possible ways of making things hang together must hang together-since he has no extra-historical Archimedean point of this sort he is doomed to be outdated. 6

Having no extra-historical Archimedean point does not mean that The Critic has nothing to say. It means, rather, that he does not ask certain questions. For example, he "does not ask how representations are related to nonrepresentations, but how representations can be seen as hanging together." 7 This is because he "cannot answer questions about the relation of the thought of our time-the descriptions it is using, the vocabulary it employs-to something which is not some alternative vocabulary."8 Since he cannot get beyond the notion of seeing how things hang together, the object for The Critic is not to construct his representations in terms of their correspondence to nonrepresentations but rather it is "to hook up our views about democracy, mathematics, physics, God, and everything else, into a coherent story about how everything hangs together." 9 For The Critic, in the new post-Philosophical culture,

telling stories about how one's favorite and least favorite literary texts hang together is not to be distinguished from-is simply a species of-the 'philosophical' enterprise of telling stories about the nature of the universe which highlight all the things one likes best and least. ${ }^{10}$

But what does The Critic tell us when he tells us his stories about the nature of the universe, both the ones which highlight the things he likes best and least, and how they all hang together? Are there some stories-perhaps the ones he likes least-which do not hang together with other stories-perhaps the ones he likes best-and, if so, how is the determination to be made? If The Critic does not have a particular favourite story to tell us about how all possible ways of making things hang together must hang together, are all such ways equally preferred? In the absence of a relation to non-representations, how will The Critic discriminate among representations which do not hang together with other representations? By way of revealing how this is done, The Critic commences by telling us how one of his least favourite texts hangs together. This is the story told by the metaphysician. 


\section{The Metaphysician}

Unlike the "all-purpose intellectual of the post-Philosophical culture," metaphysicians in general have not abandoned their "pretensions to Philosophy." Such pretensions, according to The Critic, are embodied in the terms of their "final vocabulary" which, they suppose, point to a reality beyond usage and appearance. For Rorty, the ordinary metaphysician

assumes that the presence of a term in his own final vocabulary ensures that it refers to something which has a real essence. The metaphysician is still attached to commonsense, in that he does not question the platitudes which encapsulate the use of a given final vocabulary, and in particular the platitude which says there is a single permanent reality to be found behind many temporary appearances. He does not redescribe but rather, analyses old descriptions with the help of other old descriptions. ${ }^{11}$

Unlike Rorty who cannot answer those questions about the relation of the vocabulary be employs to something which is not just some alternative vocabulary, such metaphysicians posit a relation of correspondence between the terms of their "final vocabulary" and a single permanent reality to be found behind many temporary appearances. For The Critic, however, since he cannot get beyond the notion of seeing how things "hang together," this relation is a "platitude." It is platitudinous not in the weak sense of being trite but true but rather in the strong sense of being empty and false. It is false, according to The Critic, in the dual sense that there exists neither any such "final vocabulary" nor any such "real essence" to which the terms it embodies might refer. To reject both is what it means to have "abandoned pretensions to Philosophy," and to be that "all-purpose intellectual of the post-Philosophical culture."

While there can be little doubt that metaphysicians in general will experience difficulty in demonstrating correspondence between the terms of their "final vocabulary" and that single permanent reality found behind many temporary appearances, The Critic himself does not escape unscathed. For the assertion of non-correspondence-the assertion that the presence of a term in a "final vocabulary" ensures that it does not refer to something which has a real essence-becomes part of The Critic's own "final vocabulary," and, under the ruling, must be equally "platitudinous." Similarly, just as it falls to those ordinary metaphysicians to demonstrate correspondence if their assertions are to have any epistemological warrant, so it equally falls to Rorty to demonstrate non-correspondence-to show, specifically, the nature of the derivation of his knowledge which reveals that assertions of correspondence are "platitudinous." The difficulty, of course, is that to show such derivation requires Rorty to assume the role of metaphysician himself. It assumes, in other words, the attainment of that "extra-historical Archimedean point" from which the determination of non-correspondence was made. Despite The Critic's protestations that he possesses no such extra-historical Archimedean point-it was, we recall, the reason why he was "doomed to be outdated"-to assert that there exists no relation between vocabulary and some real, extra-linguistic essence is to make what is itself a metaphysical claim. Rorty is not telling us "about how all possible ways of making things hang together must hang together" but rather he is telling us how they do not hang together. In the act of asserting that one cannot transcend language, in other words, Rorty has transcended language. The Critic has become The Metaphysician. 
But perhaps Rorty does not intend us to understand "platitude" in this strong sense and thus commit himself to metaphysical assertion. Perhaps he means something else. However, if he does not ask how representations are related to non-representations, if he cannot answer questions about the relation of the thought of our time, the descriptions it is using, the vocabulary it employs, to something which is not just some alternative vocabulary, Rorty must give some criterion of vocabulary choice. If everything, in other words, can "hang together" with everything else, Rorty may escape a "platitudinous" metaphysics but only at the cost of embracing an equally "platitudinous" relativism. 12 For if there is nothing to choose between vocabularies, what is it that privileges the vocabulary of the "post-Philosophical culture" as opposed to that of the ordinary metaphysician? What is it, in other words, that determines that it is his voice which should have an overriding claim on the attention of the other participants in the conversation?

On the basis of his metaphysics of non-correspondence between reality and appearance, between vocabulary and essence, Rorty now becomes The Metaphysician. However, unlike the common run of metaphysicians who do not question the platitudes which encapsulate the use of their "final vocabulary," Rorty knows himself "doomed to be outdated" by some later, unspecified vocabulary. The consequence is that, unlike the ordinary metaphysician who unreflectively analyses old descriptions with the help of other old descriptions, The Metaphysician does reflect on the contingency of his "re-descriptions." Realizing that it is only in passing that the stories he tells us about how his favourite and least favourite texts "hang together," The Metaphysician now becomes The Ironist.

\section{The Ironist}

What distinguishes The Ironist, according to Rorty, is that

she spends her time worrying about the possibility that she has been initiated into the wrong tribe, taught to play the wrong language game. She worries that the process of socialization which turned her into a human being by giving her a language may have given her the wrong language, and so turned her into the wrong kind of human being. But she cannot give a criterion of wrongness. So, the more she is driven to articulate her situation in philosophical terms, the more she reminds herself of her rootlessness by constantly using terms like 'Weltanschauung,' 'perspective,' 'dialectic,' 'conceptual framework,' 'historical epoch,' 'language game,' 'redescription,' 'vocabulary,' and 'irony., 13

The anguish of The Ironist can be immediately appreciated. But implicit in the assertion that one cannot give a "criterion of wrongness" is the logical point that the assertion itself abides by its own "criterion of rightness." That is, the claim must be that it is right to say that one cannot specify what it is to be wrong. In addition, there is also a further point about Rorty himself in his current embodiment. Why is it that he worries about having been initiated into the wrong tribe, the wrong language game, and consequently worries about having been turned into the wrong kind of human being if, as he claims, he lacks the criterion in terms of which tribes, language games, and human beings might be assessed? In the absence of a "criterion of wrongness," in other words, how did Rorty know that the ordinary metaphysicians' analysis of old descriptions 
with the help of other old descriptions yielded only platitudes? It may be the case that The Ironist is unable to give a "criterion of wrongness" only in respect to his own "Weltanschauung," his own language-game. Or, perhaps, is the ironic posture he purports to adopt in respect to his own frameworks and perspectives intended to serve as a foil to parry charges of self-contradiction? It is not clear, in other words, how Rorty can assert that the metaphysicians are wrong - they failed to question the platitudes which encapsulated the use of their "final vocabulary"-while simultaneously claiming that he has no "criterion of wrongness." If there is nothing to distinguish them, can any assertion in any "vocabulary"-Rorty's, the metaphysician's, or anybody else's-actually be right or wrong? If this is the case, how can Rorty make an assertion about this point or anything at all, for that matter?

For The Ironist, the solution to the dilemma raised by worrying about having been initiated into the wrong tribe and having been taught to play the wrong kind of language-game (while, simultaneously, not being able to give a "criterion of wrongness") lies simply in dismissing the concept of "criteria" itself. "Ironists," according to Rorty,

do not think of reflection as being governed by criteria. Criteria, on their view, are never more than the platitudes which contextually define the terms of a final vocabulary currently in use. ${ }^{14}$

It is clear now why Rorty claims not to possess a "criterion of wrongness." Criteria are platitudes, and this is just the sort of thing The Ironist does not possess. But if he does not think of reflection as being governed by criteria, one is left wondering by what process did he recognize platitude as platitude? How did he distinguish the ordinary metaphysician's platitude-the one which claimed that there is a single permanent reality to be found behind many temporary appearances-from the non-platitudinous claims of his own "Weltanschauung," "perspective," or "vocabulary"? Moreover, by what criterionless self-reflexive route did The Ironist determine that his own reflection is not governed by criteria? What is it, in other words, that The Ironist actually does when he reflects?

For Ironists, according to Rorty,

nothing can serve as a criticism of a final vocabulary save another such vocabulary; there is no answer to a redescription save re-re-description. Since there is nothing beyond vocabularies which serves as a criterion of choice between them, criticism is a matter of looking on this picture and on that, not of comparing both pictures with an original.

One had supposed that not having a "final vocabulary" was what it meant to be an Ironist, that it was from the rootless perspective of his "Weltanschauung" alone that Rorty rebuked the metaphysician for not questioning those platitudes which encapsulated the use of his "final vocabulary." It was freedom from criteria, those platitudes which contextually define the terms of a "final vocabulary" currently in use, which distinguished the vocabulary of The Ironist. If nothing can serve as a criticism of a "final vocabulary" save another "final vocabulary," then no distinction exists between the metaphysician's "final vocabulary" and Rorty's "Weltanschauung." The difference between them can only be Rorty's unsupported and, therefore, dogmatic assertion that it is the former not the latter which is encapsulated in platitudes. 
If nothing can serve as a criticism of a "final vocabulary" save another "final vocabulary," if there is no answer to a re-description save a re-redescription since there is nothing beyond such vocabularies or descriptions which serves as a criterion of choice between them, then it follows that any "final vocabulary," and re-re-description, must be as good as any other. Rorty's own criterionless re-descriptions are, therefore, identical in every respect to the metaphysician's "analysis of old descriptions with the help of other old descriptions," and must, likewise, fall to the level of platitude which, in the present case, happens to contextually define his final vocabulary currently in use. Where there is nothing beyond vocabularies which serves as a criterion of choice between them, where criticism is not a matter of comparing both pictures with an original, The Ironist must give some account of what he does when he "looks on this picture and on that." Rorty never adequately reveals what he does when he "looks on this picture and on that." He attempts an extended but, ultimately, a failed escape from the relativist dilemma. Relativism, he initially asserts,

is the view that every belief on a certain topic, or perhaps on any topic, is as good as any other. No one holds this view. ${ }^{16}$

If no one holds this view, what Rorty must do is to show how, where there is nothing beyond beliefs which can serve as a criterion of choice between them, one belief on a topic is not as good as any other. Quite simply, I believe that Rorty not only does not do this, but cannot do this.

What The Ironist first does is to tell a story which highlights all the things he likes least about those who claim that relativism constitutes a dilemma at all. "Relativism," The Ironist asserts, "seems a threat only to those who insist on a quick fix and knockdown arguments." 17 There are those, however, who do not "insist on a quick fix and knockdown arguments" yet who do wonder why the view that no one holds, the view that any belief on any topic is as good as any other, is not entailed in the claim that there is nothing beyond the vocabularies in which such views are articulated which can then serve as a criterion of choice between them. To repeat, why is not every belief as good as any other?

The Ironist next seeks sanctuary in "postmodemism." He asserts that

To accuse postmodernism of relativism is to try to put a metanarrative in the postmodernist's mouth. One will do this if one identifies 'holding a philosophical position' with having a metanarrative available. ${ }^{18}$

For The Ironist, as for the "postmodernist," a "metanarrative" is to be understood as having the same standing as those platitudes encapsulated within the metaphysician's "final vocabulary," and this is the major "pretension to Philosophy" which both have dropped. There is the obvious point, however, that the claim to possess no "metanarrative" is contradicted in its assertion since such assertion logically embodies its possession. One can no more claim not to possess a "metanarrative" than one can claim not to possess a "metaphysics" - that is, not to possess one's own fundamental understanding of reality, by virtue of and in terms of which any denial that one possessed a metanarrative was grounded. Rorty suggests that there is a distinction between "holding a philosophical position" with "having a metanarrative available," but it has been seen that Rorty's "Weltanschauungen," "perspectives," and "conceptual frameworks" are, in fact, identical to the "final vocabularies" of 
the ordinary metaphysician and are, by extension, indistinguishable from those "metanarratives" he claims not to have available. His appeal to "postmodernism," therefore, leaves the question of relativism untouched. For if no one, including the "postmodernist," holds the view that any belief is as good as any other, on what basis is the determination to be made? How, exactly, does the absence of a criterion of choice beyond vocabularies not lead to the view that every belief is as good as any other, the view that no one holds? ${ }^{19}$

Rorty next moves from the ad hominem-from those who "insist on a quick fix and knockdown arguments" as well as those who "try to put a metanarrative in the postmodernist's mouth"- to the theoretical. He distinguishes two kinds of theory: the "philosophical" and the "real." It is only the second for which relativism constitutes a threat:

'Relativism' only seems to refer to a disturbing view, worthy of being refuted, if it concerns real theories, not just philosophical theories. Nobody really cares if there are incompatible alternative formulations of a categorical imperative, or incompatible sets of categories of the pure understanding. We do care about alternative, concrete, detailed cosmologies, or alternative, concrete, detailed proposals for political change. ${ }^{20}$

Rorty's own distinction between "real" and "philosophical" theory, of course, itself falls into the second category. In addition to the fact that it offers no concrete, detailed proposals for political change, ${ }^{21}$ The Ironist's distinction rests upon his own "philosophical" theory, the one embodied in what it meant to be that "philosopher who has abandoned all pretensions to Philosophy." In the course of defending against charges of relativism, The Ironist simply engages in his own "philosophical" theorizing while, simultaneously, denying the relevance of such theorizing to the issue. His dismissal of relativism as worthy of being refuted only where it concerns "real theory" as opposed to "philosophical theory" merely reveals the crudely pragmatic foundations of The Ironist's own particular brand of "philosophical theory."

Despite the fact that he could give no "criterion of wrongness" since reflection was not governed by criteria at all, The Ironist is still capable of spotting a "bad inference." He maintains that "Silly relativism [consists of] the bad inference from 'no epistemological difference' to 'no objective criterion of choice." "22 The reason why it is a bad inference, for The Ironist, is that the "objective criterion of choice" is embodied in the "ability to achieve agreement on whether a particular set of desiderata has or has not been achieved.",23 However, where no one, according to Rorty, is a relativist, his "objective criterion of choice" never functions to discriminate between competing beliefs. It is, rather, little more than a consensus mechanism of confirmation for those holding a particular belief, in this case, Rorty's belief. Claims as to the fulfilment of the "objective criterion" would never be awarded, for example, to those metaphysicians who had shown similar ability to agree that a particular set of desiderata had been achieved in respect to a single permanent reality lying behind many temporary appearances. And this is because the possibility for the satisfaction of this criterion was never intended to extend to those whose beliefs on any topic were incompatible with those of The Ironist. But if "the objective criterion of choice" was not intended to extend to those whose beliefs were incompatible with those of The Ironist, does this mean that Rorty believes that the resolution of the dilemma of relativism has been achieved by the assertion 
that it is, after all, his particular belief or set of desiderata on any topic, which is the correct one? As a matter of fact, he does.

For Rorty, the "objective criterion of choice" refers to the achievement of agreement on whether a particular set of desiderata has or has not been achieved. But what is it that determines "agreement" on a particular set of desiderata? This derives, in its turn, from Rorty's "ethnocentric view of truth." According to The Ironist, there are three meanings of "true": the view that every belief is as true as any other is "self-refuting"; the view that truth has as many meanings as there are procedures of justification is "eccentric"; the third view that

there is nothing to be said about either truth or rationality apart from descriptions of the familiar procedures of justification which a given societyours-uses in one or another area of inquiry. The pragmatist holds the ethnocentric third view. ${ }^{24}$

While there may be nothing to be said about truth or rationality apart from descriptions of the familiar procedures of justification which Rorty's society uses in one or another area of inquiry, the question which arises is what, exactly, is to count as "familiar," as "our society"? Where the "objective criterion of choice" was determined by the ability to achieve agreement on whether a particular set of desiderata has or has not been achieved, or what is to count as a desideratum?

While he may have nothing to say about the Hottentot view of truth or rationality since its procedures of justification clearly do not fall within the range of the ethnocentric third view, Rorty certainly does have something to say about those who would question the view that there is nothing beyond vocabularies which serves as a criterion of choice between them. The ordinary metaphysician comes immediately to mind. ${ }^{25}$ It appears that since the metaphysician does not share Rorty's "familiar procedures of justification" (whatever they may be), and does not share the pragmatist's "ethnocentric third view" of truth, he or she, therefore, does not belong to Rorty's "given society." This is The Ironist's ultimate reply to the relativist dilemma. Every belief on a certain topic, or perhaps on any topic, is not as good as any other because it is not derived from those "familiar" procedures of justification employed by the people who belong to Rorty's society. It is those procedures which determine whether or not a particular set of desiderata has been achieved. Such a set of desiderata embody that "objective criterion of choice," which, in turn, resolved The Ironist's inability to give a "criterion of wrongness." It was this inability, it will be recalled, which resulted in his worrying about having been initiated into the wrong tribe, of having been taught to play the wrong language-game. He need not have worried. While the "all-purpose intellectual of the postPhilosophical culture" may not have been able to answer the questions about the relation of the thought, descriptions, and vocabularies of our time to something which was not just some alternative vocabulary, it so happens that there was one particular vocabulary-Rorty's vocabulary-which contained, after all, that "objective criterion of choice" apart from which there was nothing to be said about either truth or rationality.

Despite the fact that he denied the possibility of getting beyond the notion of seeing how things "hang together," 26 The Critic assumed the mantle of The Metaphysician and attained in doing so that extra-historical Archimedean point 
from which it was revealed that there was no single permanent reality to be found behind many temporary appearances. Despite the fact that Rorty claimed to be able to tell us only "how all the ways of making things hang together hang together, but not about how all possible ways of making things hang together must hang together," it turned out that it was his way of making things hang together which must hang together. For it was The Ironist's particular "objective criterion of choice," his particular "ethnocentric view of truth" which would determine whether agreement on a particular set of desiderata had been achieved. Apart from Rorty's "ethnocentric view," nothing could be said about truth or rationality.

But what stories will The Ironist tell us now about how his favourite and least favourite texts in education hang together? When he hooks up his views about democracy, mathematics, physics, God, and education into a coherent story about how everything hangs together, what interesting views will the allpurpose intellectual of the post-Philosophical culture have about the enterprise of education? The Ironist now becomes The Teacher.

\section{The Teacher}

Where The Critic felt free to comment on anything at all, things for The Teacher appear more restricted. This is so because Rorty is "dubious about the relevance of philosophy to education':

Education seems to me two quite distinct enterprises: lower education is mostly a matter of socialization, of trying to inculcate a sense of citizenship, and higher education is mostly a matter of individuation, of trying to awaken the individual's imagination in the hope that she will become able to recreate herself. I am not sure that philosophy can do much for any of these enterprises. 27

The reason why philosophy cannot do much for either of the distinct enterprises is found in the nature of both education and philosophy. The enterprises emerge as a consequence of the dispute between the right and the left over the priority of truth as opposed to freedom. For those on the right, according to Rorty, freedom can only follow from the realization of one's capacity to be rational, education must embody a process of socialization, one "of getting the students to take over the moral and political commonsense of the society as it is." 28 On the other hand, for those who maintain that truth presupposes freedom in that it can follow only from the free and open encounter of opinions, education embodies not so much a process of socialization but rather one of individuation, a process in which students come to realize that "they can rework the self-image foisted on them by their past, the self-image that makes them competent citizens, into a new self-image, one that they themselves have helped to create." 29 While the right "has pretty much kept control of primary and secondary education and the left gradually gotten control over nonvocational higher education ... the interesting differences between right and left about education are concretely political." 30 This, then, is why The Teacher was dubious about the relevance of philosophy to education, why he felt that philosophy could not do much for the distinct enterprises. The "interesting differences" about education are "concretely political"-the concern, in other words, of "real" theory rather than "philosophical" theory. 
However, despite his claim that it was the kind of theory "nobody really cared about," Rorty's initial distinction between "real" and "philosophical" theory was seen to have been derived not from "real" theory but rather from his own particular "philosophical" theory. While overtly protesting that it was the kind of theory "nobody really cared about," it was on the basis of Rorty's covert employment of his own particular "philosophical" theory that the distinction was advanced. So now Rorty's present distinction between "socialization" and "individuation" viewed as marking off the phases of the educational process can be seen to be derived not so much from any "real" theory-that is, from those alternative, concrete, detailed cosmologies or proposals for political change-but, once again, from the covert employment of his "philosophical" theory. Unlike The Teacher, both the conservatives and radicals are still attached to commonsense. What they have done, according to Rorty, is to mistakenly conceive of a "real essence" to which the presence of a term in their "final vocabularies" ensures that it refers. This can be seen when The Teacher hooks up his views on education into a coherent story about how they all "hang together.",

The Ironist may have lacked a "criterion of wrongness" and so constantly had to remind herself of her rootlessness by using terms like "Weltanschauung," "language-game," and so on, but for The Teacher matters appear more rooted, in particular when he assesses the validity of the claims to truth and freedom as embodied in the views espoused by both the conservatives and radicals. "I think the conservatives are wrong," he asserts,

in thinking that we have either a truth-tracking faculty called 'reason' or a true self that education brings to consciousness. I think that the radicals are right in saying that if you take care of political, economic, cultural and academic freedom, then truth will take care of itself. But I think the radicals are wrong in believing that there is a true self that will emerge once the repressive influence of society is removed. ${ }^{31}$.

Despite the fact that he has no "criterion of wrongness" by which he might judge these things, Rorty can now reveal both that the conservatives are wrong in thinking that we have a faculty called "reason," and that the radicals are right in thinking that truth will "take care of itself" if we take care of freedom. Despite the fact that he does not ask how representations are related to non-representations, Rorty can now also reveal that both the conservatives and radicals are wrong in thinking that the representation "self" is related to a non-representation, the self, which education brings to consciousness. For the conservatives and the radicals, like the ordinary metaphysicians before them, do not happen to share Rorty's ethnocentric view on these things, those "familiar procedures of justification" which his particular society uses in one area or another. But how did The Teacher know that education must fail in this regard? How did he know that there was no faculty of reason to which the representation "reason" was related, that there was nothing else to look on when he looked on the representation "self"'? How did he know that both the conservatives and radicals were still attached to commonsense in that they did not question these platitudes which were encapsulated in the use of their "final vocabularies"'?

The Teacher knew these things because he managed, after all, to get beyond the notion of just seeing how things "hang together." For what the metaphysicians, the conservatives, and the radicals failed to understand was that 
[t]here is no such thing as human nature, in the deep sense in which Plato and Strauss used this term. There is only the shaping of an animal into a human being by a process of socialization followed (with luck) by the self-individuation of that human through his or her own revolt against that very process. ${ }^{32}$

Rorty may not have asked how representations are related to nonrepresentations, but he certainly has the answer. Like the metaphysicians, conservatives and radicals, The Teacher also has attained that extra-historical Archimedean point, looked out, but unlike them, saw there to be no single permanent reality to be found behind many temporary appearances, no relation of representation to non-representation, and, moreover, no faculty of reason or a self to which such representations as "reason"/ and "self" might refer. As there is neither a self (which is either brought to consciousness as the conservatives would have it) nor one which will emerge once the repressive influence of society is removed (as the radicals mistakenly suppose), the consequence for education is that there remain only the processes of socialization and individuation-those distinct enterprises in respect to which philosophy, according to the Teacher, having only "dubious relevance," cannot do much. This is why, a fortiori, we should drop the notion of the philosopher as knowing something about knowing which nobody else knows, why we should drop the notion that there is something called a "philosophical method," a "philosophical technique," or a "philosophical point of view." It is why, finally, we should abandon pretensions to Philosophy, why we should put down that Glassy Essence in which nature was erroneously supposed to be mirrored, and instead, get on with the job of telling those stories about how our favourite and least favourite texts "hang together."

This paper is not the first to have taken issue with Rorty's educational philosophy. Although Rorty asserts that he is both a "postmodern" and a follower of John Dewey, his division of the educational process into the distinct stages of socialization and individuation has drawn criticism from both quarters. In her demand that we "reconceptualize education in postmodern terms," for example, Lynda Stone rejects Rorty's linear conception of the educational process. ${ }^{33}$ In similar fashion, although from a Deweyan perspective, William Hare points out that Rorty has simply failed to show grounds for his sequential ordering of the distinct stages, for claiming that schooling constitutes two processes rather than one. ${ }^{34}$ Stone's linearity and Hare's sequentiality, however, present no obstacle for Rorty. He points out that within the socialization process itself "we have the good luck to live in a society which has managed to make social criticism part of the tradition which lower education is supposed to hand down." 35 Of course, one could add that our "good luck" also serves to render Rorty's entire concept of the "distinct processes of education" problematic. A further critique of Rorty's Deweyan credentials comes from Kenneth Wain who maintains that no relationship exists between Dewey's concept of "growth" and Rorty's concept of "irony" with the consequence of divergent emphases in the educational process. ${ }^{36}$ Not all comments on Rorty are critical. Alven Neiman hails Rorty's "irony" as "the necessary component of the temperament that would take growth or self-creation rather than 'Freedom,' 'Truth,' or the fulfilment of 'human nature' as definitive of human striving properly understood." Indeed, for Neiman, such irony, "to be satisfactory, must even be ironic towards 
itself." 37 As the fullest embodiment of that necessary component definitive of human striving properly understood, one wonders if one could then adopt a posture of irony in respect to one's irony about one's initial irony?

Rather than a critique from without-that is, from Rorty's failure to satisfy the criteria of different philosophical perspectives, the present paper has attempted a critique from within-that is, from an internal analysis of Rorty's own claims. More specifically, I have attempted to show that Rorty's claim to be "post-Philosophical," to have transcended metaphysics and epistemology in the "post-modern" style, has encountered profound difficulties. More specifically, I have attempted to show that his concept of "hanging together" does not itself hang together because it is either self-contradictory or self-refutingly relativistic. Finally, where Rorty conceives education in terms of those "quite distinct enterprises" of "socialization" and "individuation," I have attempted to show that it is not so much philosophy itself but rather Rorty's conception of it which cannot, in his own words, "do much for any of these enterprises."

\section{Notes}

1 Richard Rorty, Philosophy and the Mirror of Nature (Princeton: Princeton University Press, 1979), p. 123.

\section{According to Rorty,}

To drop the notion of the philosopher as knowing something about knowing which nobody else knows so well would to be to drop the notion that his voice has an overriding claim on the attention of the other participants in the conversation. It would also be to drop the notion that there is something called a 'philosophical method' or 'philosophical technique' or the 'philosophical point of view which enables the professional philosopher, ex officio, to have interesting views about, say, the respectability of psychoanalysis, the legitimacy of certain dubious laws, the resolution of moral dilemmas, the 'soundness' of schools of historiography or literary criticism, and the like. Philosophers often do have interesting views on such questions, and their professional training as philosophers is often a necessary condition for their having the views they do. But this is not to say that philosophers have a special kind of knowledge about knowledge (or anything else) from which they draw relevant conclusions. Ibid., pp. 392-393.

3 Richard Rorty, Consequences of Pragmatism: Essays: 1972-1980 (Minneapolis: University of Minnesota Press, 1982), p. xl.

${ }^{4}$ Where capitalized, the terms "The Critic," "The Metaphysician," and

"The Ironist" refer to Rorty himself.

5 Consequences of Pragmatism, op. cit., p. xxxviii.

6 Ibid., p. xl. (Italics in original)

7 Ibid., p. 92

8 Ibid., p. xl.

9 Ibid., p. 168.

10 Richard Rorty, Objectivism, Relativism and Truth: Philosophical Papers, Volume I (Cambridge: University of Cambridge Press, 1989), p. 79.

11 Richard Rorty, Contingency, Irony, and Solidarity (Cambridge: Cambridge University Press, 1989), p. 74. 
12 Rorty does not clearly distinguish between "analysing" and "redescribing." However, as Charles Taylor points out, where Rorty's "redescriptions" serve to " 'buttress' a new way of seeing things," there arises,

the necessity of some constraints of consistency on the discourse of redescription. ... And when he quotes Sellars's definition of philosophy as an 'attempt to see how things, in the broadest possible sense of the term, hang together in the broadest possible sense of the term,' this too only makes sense if one recognizes such constraints; otherwise, anything could 'hang together' with anything, and there would be nothing to 'attempt to see' here. [Charles Taylor, "Rorty in the Epistemological Tradition," in Alan R. Malachowski (Edit.) Reading Rorty: Critical Response to Philosophy and the Mirror of Nature (and Beyond) (Cambridge: Basil Blackwell Inc., 1990), p. 259.]

13 Contingency, Irony, and Solidarity, op. cit., p. 75.

14 Ibid.

15 Ibid., p. 80

${ }^{16}$ Consequences of Pragmatism, op. cit., p. 166.

17 Objectivism, Relativism, and Truth, op. cit., p. 66.

18 Ibid., p. 202.

19 In spite of the fact that he objects to those who would try to put a metanarrative in the postmodernist's mouth, Rorty ("The Dangers of Over-Philosophication-Reply to Arcilla and Nicholson," Educational Theory, 40(1), (Winter) 1990 , p. 43) states that

I have doubts about whether there is an identifiable phenomenon called 'postmodernism' because I see no sharp breaks in Western political or cultural life since the time of the French Revolution. I would agree that in our present 'age of the world picture' (to use Heidegger's term), there is increasingly less respect for the Enlightenment divisions between spheres of culture. However, the process of breaking down these divisions seems to me to begin with Hegel and to be pretty well complete in Dewey. If Dewey is to count as a postmodem, then I am not sure that 'postmodern' is the word we want.

20 Consequences of Pragmatism, op. cit., p. 168.

21 If his "For a More Banal Politics" (Harper's Magazine, 284(1704), (May)1992, pp. 16-21) is any example, Rorty's own proposals for political change can hardly be called "detailed, alternative, or concrete." For example, in respect to the response of the American left to the collapse of Soviet communism, he writes that,

Not only are we going to have to stop using the term 'capitalist economy' as if we knew what a functioning non-capitalist economy looked like, but we are going to have to stop using the term 'bourgeois cultures' as if we knew what a viable non-bourgeois culture in an industrialized society would look like. (p. 16)

Indeed, Richard Bernstein ("One Step Forward, Two Steps Backward: Richard Rorty on Liberal Democracy and Philosophy," Political Theory, 15(4), (November)1987, pp. 538-563) maintains that far from advancing concrete and detailed proposals for political change, Rorty's political theory constitutes "little more than an apologia for the status quo" (p. 541). 
22 Objectivism, Relativism and Truth, op. cit., p. 89.

23 Ibid., p. 90.

${ }^{24}$ Ibid., p. 23.

25 Recall the metaphysician is the one who did not question the "platitude which said that there is a single permanent reality to be found behind many temporary appearances, the one for whom relativism does seem to refer to a "disturbing view," one "worthy of being refuted."

26 Recall that Rorty did not ask how representations are related to nonrepresentations but only how representations can be seen as "hanging together."

27 "The Dangers of Over-Philosophication," op. cit., p. 41.

28 Richard Rorty, "Education Without Dogma: Truth, Freedom, and our Universities," Dissent, (Spring)1989, pp. 198-204, p. 199.

${ }^{29}$ Ibid., p. 200.

${ }^{30}$ Ibid., p. 199.

31 Ibid., p. 200

32 Ibid.,

33 In her "Contingency: The 'Constancy' of Teaching," (Teachers College Record, 94(4), (Summer)1993, pp. 815-835), Lynda Stone claims that,

What is needed is to reconceptualize education in postmodern terms by doing away with Rorty's linear view of socialization followed by individuation. In a model of praxis, socialization need not precede criticism. Both can occur as ongoing processes throughout schooling. (p. 823)

34 According to Hare, ("Content and Criticism: the Aims of Education," Journal of Philosophy of Education, 29(1), (March)1995, pp. 47-60)

Dewey maintained that education is a unified process and believed that such a view was essential if continuing intellectual and moral momentum was to be satisfied. . . . Rorty has given us no reason whatever to view socialization and critical thinking as two processes which must be pursued in sequential order rather than two aspects of one process which may be pursued simultaneously. (pp. 55-56)

35 “"The Dangers of Over-Philosophication," op. cit., p. 42

36 Wain ("Richard Rorty, Education, and Politics, Educational Theory, 45(3), (Summer)1995, pp. 395-410) took issue with Alven Neiman's identification of Rorty's "irony" and Dewey's "growth" (see note \#37), maintaining that "the resemblance between the two notions is untenable, if analysed in relation to bow Dewey understood 'growth' (as a purely social phenomenon), and how Rorty understood 'irony' (as a totally private matter)" (p. 397).

37 Alven Neiman, "Ironic Schooling: Socrates, Pragmatism and the Higher Learning," Educational Theory, 41(4), (Fall)1991, pp. 371-384. 